\title{
REPARACIÓN INTEGRAL DE VÍCTIMAS DE PROCEDIMIENTOS DE CIRUGÍA PLÁSTICA CON FINES ESTÉTICOS A TRAVÉS DEL SEGURO DE RESPONSABILIDAD CIVIL
}

José López Oliva*

\section{Resumen}

En el ejercicio de las actividades médico-sanitarias se pueden ver transgredidos derechos de los usuarios como la vida e integridad física y mental por parte de los prestadores de salud que realizan procedimientos de cirugía plástica estética. Pueden ser profesionales liberales cuando se hace referencia a la responsabilidad médica o prestadores sanitarios en el caso de la responsabilidad de las clínicas que realizan procedimientos estéticos. Estas personas que son eventuales causantes de daños pueden generar perjuicios al paciente, sus causahabientes y perjudicados indirectos. El presente escrito es producto de una investigación de tipo exploratoria de revisión, mediante el cual se indaga, compila, revisa e integra el resultado de una investigación bibliográfica, en la que se agruparon y sistematizaron los documentos relacionados con el tema objeto de la investigación. El tema es la responsabilidad médico-sanitaria derivada de procedimientos estéticos y el seguro de responsabilidad civil que cubre dicha responsabilidad, relacionando lo anterior con la reparación integral de las víctimas del hecho médico-sanitario dañoso.

\section{INCLUSIVE COMPENSATION THROUGH LIABILITY INSURANCE FOR AESTHETIC PLASTIC SURGERY VICTIMS}

\begin{abstract}
In medical-sanitary practice, user rights such as life and physical and mental integrity may be transgressed by healthcare providers who perform aesthetic plastic surgery procedures. They may be liberal professionals, when referring to medical liability, or sanitary providers in the case of the liability of clinics which carry out aesthetic procedures. These individuals who could eventually cause harm may generate injuries to patients who are their assignees and indirect negatively affected subjects. This article results from an exploratory research through which we inquired, compiled, reviewed and integrated the results of a literature review which consolidated and standardized documents related to the research topic. The topic is medical-sanitary liability derived from aesthetic procedures and the civil liability insurance coverage of said responsibility relating the latter with the inclusive compensation of the victims of the adverse medical-sanitary event.
\end{abstract}

Fecha recibido: julio 16 de 2012 - Fecha aceptado: abril 3 de 2013

* Docente investigadorTC Universidad Militar Nueva Granada. Coordinador de la Línea de Investigación en Derecho de la Responsabilidad y de Seguros UMNG. Magister en Derecho con enfoque en Responsabilidad y Seguros, Universidad de Los Andes. Magister de la Universidad Carlos III de Madrid
(España). Especialista en Derecho Comercial de la Universidad Pontificia Bolivariana de Medellín, Derecho Penal y Probatorio de la Universidad del Rosario. Estudios de doctorado en Derecho, Universidad de Buenos Aires (Argentina). Docente certificado a nivel internacional por Life Office Management Asociation, Inc-Loma, Atlanta-Georgia (USA). Correo electrónico: jose.lopez@unimilitar.edu.co 


\section{Introducción}

A las víctimas del hecho médico-sanitario dañoso en procedimientos estéticos como la rinoplastia por ejemplo, se les deben garantizar los derechos fundamentales a la salud, a la verdad, a la justicia y a la reparación integral; esta última se logra mediante la suscripción por parte del prestador en salud de un seguro de responsabilidad médica y sanitaria con coberturas, sin exclusiones y con límites de indemnización proporcionales al riesgo trasladado, entre otros, que garanticen la indemnización de las víctimas de procedimientos estéticos de manera integral. Víctimas que en el contrato de seguro de responsabilidad civil para prestadores médico-sanitarios, se constituyen como beneficiarias de la póliza.

Los sistemas normativos integran ordenamientos jurídicos relacionados con la responsabilidad médicosanitaria y los seguros para prestadores de servicios en salud; ordenamientos cuyo propósito es, entre otras, la reparación integral a las víctimas de los daños causados en la relación médico e institución en salud y paciente. No obstante, cuando el prestador en salud es condenado por mala praxis médica por ejemplo, el operador judicial ordena al dañador la reparación a las víctimas de procedimientos estéticos, pero el patrimonio del causante del daño puede ser insuficiente o inexistente.

A las víctimas de procedimientos estéticos se les debe garantizar su derecho a la verdad, a la justicia pero no a la reparación integral de los perjuicios causados por el prestador en salud, quien puede ser condenado al pago de la indemnización a favor del dañado, pero ésta no se garantiza ante la imposibilidad de reparación, tal como se señaló en el párrafo anterior. La reparación a las víctimas no se centra solo en el usuario de los servicios en salud, sino que trasciende a sus causahabientes que necesariamente deben ser familiares y además a quienes no lo son, denominadas víctimas indirectas.
Este trabajo presenta el siguiente problema de investigación: ¿se puede garantizar la indemnización integral a las víctimas de procedimientos médicos estéticos?

La hipótesis presentada como respuesta a la pregunta antes señalada, es que se puede garantizar la indemnización integral de las víctimas de procedimientos médicos plásticos estéticos, mediante la suscripción del seguro de responsabilidad civil para las personas que realicen estas actividades. Seguro en el cual el tomador asegurado es el prestador en salud y el beneficiario es el paciente, causahabiente o perjudicado indirecto.

Para demostrar la hipótesis presentada, el texto se desarrolla de la siguiente manera: en primer lugar ${ }^{1}$ se hace alusión a la víctima del hecho médico-sanitario dañoso originado por procedimientos estéticos, para en seguida ${ }^{2}$ establecer los derechos del paciente, sus causahabientes y perjudicados indirectos, víctimas del daño médico-sanitario en su calidad de beneficiarios de la póliza de responsabilidad civil para prestadores médicos que realizan procedimientos estéticos; a continuación ${ }^{3}$ se argumenta la hipótesis presentada en este escrito, relacionada con el seguro de responsabilidad civil y su incidencia en la indemnización integral a las víctimas del daño médico estético, para ${ }^{4}$ por último ${ }^{5}$ presentar unas breves conclusiones o hallazgos del trabajo de investigación realizado.

\section{Las víctimas del hecho médico derivado de procedimientos de cirugía plástica estética y afines}

Se considera víctimas a las personas, en este caso pacientes, que de forma individual o colectiva han sufrido lesiones físicas o mentales, daños, sufrimiento emocional, menoscabo de derechos fundamentales como la salud o pérdidas financieras, producto de acciones $\mathrm{u}$ omisiones que vulneran el ordenamiento legislativo. ${ }^{1}$

I Organización de las Naciones Unidas (ONU). Oficina del Alto comisionado de las Naciones Unidas para los Derechos Humanos. Declaración sobre los principios fundamentales de justicia para las víctimas de delitos y del abuso de poder; adoptada por la Asamblea General en su resolución 40/34, de 29 de noviembre de 1985. Disponible en: http://www2.ohchr.org/spanish/law/delitos.htm recuperado: 13/04/2012. 
La víctima del daño que provenga de procedimientos de cirugía plástica estética ${ }^{2}$, tiene la facultad de acudir ante los organismos jurisdiccionales, con el objetivo de demandar la protección de sus derechos fundamentales, o la reparación de los perjuicios ocasionados por el prestador en salud.

Para determinar que una persona ha sido víctima de un daño médico-sanitario ${ }^{3}$ como producto de la prestación del servicio por parte de los agentes en salud, se establece que el hecho dañoso fue consecuencia de un acto médico; acto en el que el paciente es potencial víctima de un procedimiento denominado meloplastia por ejemplo, por parte del sujeto prestador en salud, quien en las relaciones asistenciales puede convertirse en victimario.

Procedimiento que "es quizá la cirugía de rejuvenecimiento que mayores cambios trae al paciente, pues en ella se manejan las arrugas de las mejillas, los surcos nasogenianos y el cuello". ${ }^{4}$ Los pacientes se sienten motivados por el citado tratamiento, que "se conoce más comúnmente con su nombre en inglés, face lift, aunque, este término implica también otras cirugías". ${ }^{5}$
En esta relación asistencial, es el prestador de medicina estética sanitario "quien está en capacidad de orientar, mejorar o sanar, o cuando menos aliviar el sufrimiento de acuerdo a sus capacidades y al tipo de enfermedad", o necesidad de mejoría en su aspecto físico que el paciente requiera. Paciente catalogado como usuario o consumidor $^{7}$ de los servicios ${ }^{8}$ antes señalados.

Así mismo, se ha definido a la víctima, en este caso el usuario de los servicios de medicina estética, como la persona "sobre la cual se materializa la conducta" como consecuencia de eventos adversos ${ }^{10}$, presentados dentro de la prestación sanitaria. Eventos que pueden producir la vulnerabilidad de bienes jurídicos tutelados como la vida y la integridad física del paciente, quien corre el riesgo de ser dañado dentro del procedimiento estético. La vida como un proceso dinámico que es, presenta "una invariante compartida: la contingencia del riesgo. El manejo y el grado de asunción del riesgo caracterizan a una persona e incluso a una sociedad" ", sometida a las prestaciones sanitarias.

La prestación del servicio médico-sanitario incluido el de procedimientos médicos estéticos, es de gran

2 Para los efectos del presente escrito hay que precisar lo siguiente; existen cirugías plásticas con fines estéticos y cirugías plásticas con fines reconstructivos. En el escrito se hará alusión a las primeras a las cuales se les denominará como procedimientos estéticos, medicina estética, cirugía estética, daño estético, procedimientos médicos estéticos, cirugia plástica estética. Estos términos se deberán tomar como lo mismo. La cirugía plástica con fines estéticos es un procedimiento relacionado con la vanidad y la armonía; de lo contrario, los procedimientos de cirugía plástica con fines reconstructivos están relacionados con aspectos fundamentales del ser humano.

3 La responsabilidad médico-sanitaria hace referencia a la responsabilidad en que incurren los profesionales liberales del área de la salud (responsabilidad médica) quienes pueden causar daño a los usuarios de los servicios relacionados con procedimientos plásticos estéticos y la responsabilidad sanitaria se relaciona con los daños causados por las personas jurídicas privadas o públicas prestadoras de los servicios antes mencionados.

4 Galán Ricardo, Castillo Ana Luz. Cirugías estéticas: todo lo que usted necesita saber. Bogotá Editorial Norma 2001. P.9I

5 Ibidem.

6 Guzmán Mora Fernando. El acto médico. Consideraciones esenciales. Disponible en: http:// uww.Médicolegal.com.co/Ediciones/2 1998/actomed consi. htm.Recuperado: 15/04/2012.

7 El seguro es un negocio económico plasmado en un contrato regido por los principios en material civil y mercantil. Estos contratos se "armonizan" con la legislación de defensa de los derechos del consumidor y del usuario, ley 24.240, y la Constitución nacional, que a partir de 1994, no solo incorporó formulaciones normológicas, sino que otorgó jerarquía especial a los tratados internacionales, algunos de los cuales - entendemos - son aplicables a la materia de seguros. Cfr. GHERSI,CarlosAlberto.Contrato de Seguro. BuenosAires:Editorial de Astrea. 2007. P.8. ZENTHER; Diego, Universidad de Buenos Aires, módulo Derecho y Salud, clase magistral, Doctorado en Derecho, Buenos Aires, enero de 2012.

8 TRIGO REPRESAS Félix A, STIGLITZ S. El seguro contra la responsabilidad civil profesional del médico. Buenos Aires: Editorial ASTREA. 1983 p. 29.

9. Corte Constitucional, sentencia C-228 de 2002, M.P. Manuel José Cepeda, Eduardo Montealegre. La alta Corporación al hacer referencia a las víctimas y los perjuicios hace la siguiente reflexión:"A partir del año 2002, definió claramente lo que se debia entender por victima...(y)...perjudicado...Según el alto Tribunal, victima (es la persona respecto de la cual se materializa la conducta...), perjudicado (tiene un alcance mayor en la medida en que comprende a todos los que han sufrido un daño asi no sea patrimonial (...)"

10 Entendemos como eventos adversos a las lesiones o complicaciones involuntarias que ocurren durante la atención en salud, los cuales son atribuibles a ésta más que a la enfermedad subyacente y que pueden conducir a la muerte, la incapacidad o al deterioro en el estado de salud del paciente, a la demora del alta, a la prolongación del tiempo de estancia hospitalizado y al incremento de los costos de no-calidad. Por extensión, también aplicamos este concepto a situaciones relacionadas con procesos no asistenciales que potencialmente pueden incidir en la ocurrencia de las situaciones arriba mencionadas." Cfr. República de Colombia, Ministerio de Protección Social, resolución número 1446 del 8 de mayo de 2006, "Por la cual se define el Sistema de Información para la Calidad y se adoptan los indicadores de monitoria del Sistema Obligatorio de Garantia de Calidad de la Atención en Salud".

II GHERSI, Carlos Alberto. Op.cit.p.3 
relevancia en la vida de los seres humanos; es el paciente quien acude ante el profesional de la salud de forma voluntaria y libre, situándose en posición de "dependencia cognoscitiva; se pone en sus manos, 'confía', ya que no puede entender"'2 el origen de su enfermedad, la sintomatología que presenta o cuál es la solución ante la inconformidad en su aspecto físico por ejemplo.

Es el paciente quien decide trasladar su situación de enfermedad o impotencia, a quien tiene el conocimiento científico necesario para la solución de su condición física o de salud, acudiendo al profesional sanitario quien tiene la obligación de salvaguardar sus derechos fundamentales en el ejercicio de su actividad; actividad que debe estar ajustada a la diligencia ${ }^{13}$, prudencia, pericia y observancia de los protocolos galénicos en procedimientos médicos estéticos.

Protocolo como el siguiente: el paciente que acude a la institución de salud debe ser informado de forma veraz por el médico estético, de todos los procedimientos que se van a practicar al paciente y los riesgos inherentes a los mismos. Riesgos que serán indicados en un documento denominado consentimiento informado, que constituye una prueba declarativa relevante dentro de un proceso judicial. En algunos casos el operador en salud exime su responsabilidad con el debido diligenciamiento de este documento ${ }^{14}$, argumentando por ejemplo, que el daño se generó a consecuencia de un caso fortuito o por culpa exclusiva de la víctima al no seguir las recomendaciones del cirujano plástico estético.

Por otro lado el profesional experto en procedimientos estéticos, puede argumentar que no se logró el objetivo esperado en el paciente sometido a una gluteoplastia de aumento por ejemplo, a pesar de haberse empleado todos los medios y toda la diligencia que le era posible prestar (...). "Que se presentó un accidente imprevisible debido al estado incierto y delicado del organismo del paciente (...). Que el daño sufrido por el paciente se debió exclusivamente al accionar de otro médico, al de una enfermera o a una falla de hospital. ${ }^{15}$

Gluteoplastia de aumento que es "una técnica quirúrgica encaminada a aumentar el tamaño de las nalgas en aquellas pacientes que las tienen con poca proyección. El principio de la cirugía es el mismo de la mamoplastia de aumento, es decir, adicionar volumen mediante el uso de prótesis rellenas de silicona." ${ }^{16}$ En este sentido hay que señalar que en los procedimientos indicados antes, "el volumen que se va a implantar se establece mediante acuerdo entre el cirujano plástico y la paciente, y por lo general se colocan entre 300 y 500 centímetros cúbicos." 17

Por último puede aducir el médico estético, "que el fracaso de la intervención se debió a que el paciente no cumplió las instrucciones posoperatorias (...) y por ello el resultado se debió a la culpa exclusiva de la víctima."18

12 LORENZETTI, Ricardo Luis. Responsabilidad Profesional. Buenos Aires: Editorial Abeledo Perrot 1995. p.75

13 TRIGO REPRESAS Félix A. STIGLITZ S. Op. Cit. P.24

$14 \mathrm{El} \mathrm{consentimiento} \mathrm{informado} \mathrm{debe} \mathrm{cumplir} \mathrm{con} \mathrm{los} \mathrm{datos} \mathrm{que} \mathrm{se} \mathrm{enuncian} \mathrm{a} \mathrm{continuación:} \mathrm{1.} \mathrm{La} \mathrm{capacidad} \mathrm{del} \mathrm{paciente} \mathrm{para} \mathrm{decidir} \mathrm{sobre} \mathrm{la} \mathrm{realización} \mathrm{de} \mathrm{los}$ procedimientos. 2. La manifestación expresa del paciente de conocer la verdad acerca de su enfermedad. 3. Las necesidades de los procedimientos médicos y el tratamiento a seguir. 4. El paciente debe saber la verdad sobre los riesgos del tratamiento o procedimiento médico-sanitario a seguir. 5. El prestador sanitario debe establecer las consecuencias probables de la información suministrada al paciente. LLAMAS POMBO Eugenio, la responsabilidad civil del médico. EditorialTrivium. Madrid. 1988, pp. 162 y ss. En:LOMBANA VILLALBA. Jaime. Derecho Penal y responsabilidad médica, $3^{\text {a }}$. Ed. Medellín: Editorial Diké. 2007. p. 81

15 Cfr. Código Civil Colombiano. Bogotá:Leyer. 2012. p. 38I. El artículo 2344 señala:"Si un delito o culpa ha sido cometido por dos o más personas, cada una de ellas será solidariamente responsable de todo perjuicio procedente del mismo delito o culpa, salvo las excepciones de los artículos 2350 y 2355 ". Cuando existe pluralidad de victimarios se configuran las denominadas obligaciones "conexas","concurrentes" o in solidum, en las cuales dos o más sujetos están obligados a reparar los daños a un acreedor.

16 Op. Cit. GALAN, Ricardo. CASTILLO,Ana Luz. Op. cit. p. 230. Igualmente existe el procemiento denominado rinoplastia "que consiste en la esqueletonización del armazón osteocartilaginoso, con una ulterior adaptación de los tejidos blandos a la nueva forma del armazón nasal, realizando esta operación mediante incisiones mucosas, intranasales, sin realizar ninguna incisión cutánea". Disponible en:http://www.definicionesdemedicina.com/rinoplastia-cerrada/ recuperado el: 10/06/2012.

17 Op. cit. GALAN, Ricardo. CASTILLO, Ana Luz. op.cit. p. 230.

18 YEPES RESTREPO, Sergio. La Responsabilidad Civil médica. Medellín: Editorial Diké. 1992. p. 72 
El paciente tiene derecho a conocer sus condiciones de salud, los procedimientos a realizar en su organismo, los riesgos inherentes al procedimiento estético, entre otros, y por lo tanto el galeno debe informar o instruir $^{19}$ al usuario sobre todos los procedimientos a realizar y sus riesgos respectivos. Esta información se suministra de acuerdo con las competencias y conocimientos científicos del profesional en procedimientos estéticos, aplicados en el diagnóstico médico y en la formulación del informe pertinente. ${ }^{20}$ Contrario sen$s u$, el paciente también tiene derecho a no conocer la verdad sobre su estado de salud, decisión que debe ser manifestada al prestador médico quien debe respetar y acatar la voluntad del paciente.

No obstante, el prestador sanitario diferente al profesional cuya actividad se centra en procedimientos estéticos, puede vulnerar el derecho a la verdad, cuando el profesional de la medicina considera que la información puede agravar el estado de salud del usuario de los servicios médicos. Existen ciertas condiciones que deben cumplirse para abstenerse de suministrar la información al paciente, dentro de las que se encuentran:

- Información concreta al paciente pero no para todos los procesos.

- El perjuicio para el paciente por suministrar la información ha de ser muy probable y establecida como muy grave. La información debe ser veraz, es decir, el profesional si bien podrá abstenerse de informar sobre todos los procesos médicos y el estado de salud del paciente, lo que transmita debe ser cierto. La mentira por parte del prestador en salud no es admisible en la relación médicoasistencial, porque a mediano plazo puede generar más mal que bien, rompiendo la confianza en el proceso terapéutico.
- La abstención debe presentarse siempre de manera excepcional, no debe ser considerada como regla general en los procedimientos médicos.

- El profesional de la salud que quiera hacer uso de la excepción debe justificar en la historia clínica su decisión de abstenerse de informar.

El profesional que decida optar por la excepción en el deber de información, se compromete a buscar las herramientas que faciliten en el menor tiempo posible, revertir las circunstancias que justificaron la decisión de abstención. ${ }^{21}$

\section{Derechos del paciente, causahabientes y perjudicados indirectos, víctimas del daño en procedimientos estéticos como beneficiarios de la póliza de responsabilidad civil}

En la actualidad se ha presentado un incremento de los procesos judiciales contra los prestadores de los servicios médicos estéticos, muchas veces de manera injustificada, por la ejecución de hechos sanitarios dañosos causados a los usuarios de los mismos; hechos que causan perjuicios a los pacientes como víctimas directas de procedimientos estéticos como la ritidectomía por ejemplo, consistente en la "eliminación de las arrugas de la piel alrededor de la cara" 22 , el cual es conocido popularmente como "lifting". Se generan perjuicios que lesionan los derechos, igualmente, de los causahabientes familiares de la víctima directa o de las indirectas no parientes.

La víctima directa o indirecta del procedimiento estético busca la reparación de los perjuicios causados a consecuencia del procedimiento médico dañoso a cargo del prestador estético, recurriendo a las normas

19 LE TOURNEAU, Philippe. La responsabilidad civil profesional. Bogotá:Editorial Legis. 2006. Pp II 6 y ss.

20 La protección integral significa que el Sistema de Seguridad social en Salud debe atender la salud de la población en cuanto a la educación, información y fomento de la salud y la prevención, diagnóstico, tratamiento y rehabilitación, en cantidad, oportunidad, calidad y eficiencia Cfr. GALINDO VÁCHA, Juan Carlos. La salud y su aseguramiento en Argentina, Chile, Colombia y España. Madrid: Editorial Fundación Mapfre. 20II p. 69. Con anterioridad, se tenía una visión mágica del profesional en salud, quien "tenía especial fundamento en el monopolio del conocimiento que lo ubicó en un lugar de privilegio dentro del contexto social” LOVECE, Graciela. Información y Publicidad del Servicio Médico. Buenos Aires: Editorial Astrea. 2004. p. 201.

2 I BARBERO GUTIERREZ, Javier, el derecho del paciente a la información: el arte de comunicar, disponible en: http://mww.cfnavarra.es/salud/anales/textos/ vol29/sup3/suple3a. html recuperado: 20/04/2012

22 KLAJN, Diana Silvia. Diccionario enciclopédico de enfermería. Argentina: Ediciones Médicas Panamericana. 1996. p. I.I25. 
con el objetivo de demandar la reparación integral por el daño galénico; reparación determinada en un valor económico que debe ser cancelado por el profesional de procedimientos estéticos a las víctimas del daño médico, como consecuencia de la relación médicopaciente.

Relación que se presenta entre el galeno experto en procedimientos de cirugía plástica con fines estéticos y afines y el usuario del servicio en salud, que está determinada de la siguiente manera: "1. Por decisión voluntaria y espontánea de ambas partes. 2. Por acción unilateral del médico, en caso de emergencia. 3. Por solicitud de terceras personas. 4. Por haber adquirido el compromiso de atender a personas que están a cargo de una entidad privada o pública"23, y/o al ente sanitario -clínica u hospital- cuando este cause daños al paciente.

La protección de los derechos a la vida y a la integridad física que involucra el ejercicio de la medicina estética, permiten que esta profesión sea una de las más importantes en la historia de la humanidad; las personas confían en la pericia de los prestadores del servicio para mejorar su aspecto físico o sus condiciones de salud ${ }^{24}$ y vida; prestadores que tienen como propósito “(...) reducir o eliminar el sufrimiento, la disminución o el control del dolor, así como la lucha contra la muerte, como expresión del instinto natural de proteger y querer conservar" ${ }^{25}$ la existencia humana de los pacientes.
La salud en países como Colombia, es considerada como un derecho fundamental porque se "identifica como un predicado inmediato del derecho a la vida, entendido éste como la obligación y garantía de protección por parte del Estado, y más aún en aquellas situaciones donde la prestación de los servicios de salud son la herramienta para salvaguardar este derecho"26; de manera que "atentar contra la salud de las personas equivale a atentar contra su propia vida." 27

Así mismo, se indica que el derecho a la salud ${ }^{28}$ es inherente a la dignidad humana, por lo que el Estado debe protegerlo y garantizarlo, permitiendo el libre desarrollo de los asociados dentro del marco de un Estado social de derecho. ${ }^{29}$

De igual manera la salud del paciente que se somete a procedimientos estéticos se relaciona con el bloque de constitucionalidad de los tratados internacionales de derechos humanos. ${ }^{30}$

Para la protección a los derechos de los usuarios del servicio en salud que han sido víctimas de la prestación médica-sanitaria dedicada a procedimientos médicos estéticos, se crean disposiciones normativas que buscan sancionar al profesional de la salud, enmarcada en la responsabilidad civil, penal, estatal o ético disciplinaria, con el fin de castigar los hechos dañosos ocasionados y lograr la indemnización de los perjuicios generados al paciente víctima de los mismos.

23 Cfr. Congreso de la República de Colombia, Ley 23 de 198I.Art. 5, capítulo II. Diario Oficial No. 35.7II, del 27 de febrero de 1981 “Por la cual se dictan normas en materia de ética médica".

24 También se reconoce que la salud está influida por decisiones que se toman a todos los niveles del gobierno y en la vida cotidiana del individuo. Cfr. GALINDO VÁCHA, Juan Carlos Op.cit. p. 18

25 LOMBANA VILLALBA. Jaime. Op.cit. p. 25

26 Corte Constitucional de Colombia, sentencia T-534 de 1992, M.P. Ciro Angarita Barón.

27 Corte Constitucional de Colombia, sentencia T-484 de 1992, M.P. Fabio Morón Díaz. Cfr. LOPEZ OLIVA, José Olmedo. Revista Laboratorio Actual.Asociación de Bacteriólogos Javerianos. Bogotá, octubre, 2007, N 40. pp. 33-36

28 La salud en el ámbito institucional esta vista bajo dos ópticas diferentes. En primer lugar como derecho fundamental de los niños (art 44), de las personas de tercera edad (arts. 46 y 47) y de las personas en general (art 48). En segundo término, la salud como servicio público obligatorio a cargo del Estado, cuya actividad será reglamentada por el legislador y dirigida, coordinada y controlada por la organización estatal. Cfr. GALINDO VÁCHA, Juan Carlos. Op.cit. p. 27. OLANO GARCIAA, Hernán Alejandro. Constitución Política de Colombia. Bogotá: Doctrina y Ley. 2011.pp. 192 y ss.

29 Modelo de Estado que se funda en "el respeto de la dignidad humana y tiene como uno de sus fines esenciales garantizar la efectividad de los principios y derechos". En: Corte Constitucional de Colombia, sentencia T. 534 de 1992, M.P. Ciro Angarita Barón.

30 Corte Constitucional de Colombia, sentencia T-57I de 2002, M.P. Jaime Córdoba Triviño. 
Las acciones civiles y penales derivadas de daños generados en procedimientos estéticos propenden por la defensa de los derechos fundamentales del paciente, sus causahabientes o terceros, entre los que se cuenta el derecho a la reparación integral de los perjuicios. Estas acciones también se inician cuando el causante del hecho dañoso es el Estado ${ }^{31}$, representado por los servidores públicos que ejercen funciones médico-sanitarias, o por particulares en el ejercicio de funciones públicas, y por los entes estatales médicoasistenciales $^{32}$ que pueden incumplir con sus deberes sanitarios.

El prestador del servicio médico-sanitario tiene dos deberes principales, por un lado el de "contribuir al bienestar de su paciente ${ }^{33}$, a quien se le practica un procedimiento de mamoplastia ${ }^{34}$ como muestra, y de otro lado, el de abstenerse de causarle un daño. ${ }^{35}$. En este sentido, la prestación de los servicios de medicina estética tiene como objetivos principales, la conservación de la integridad física y de la vida ${ }^{36}$ del paciente, con lo cual el médico debe actuar con la debida diligencia, pericia, prudencia y observancia de todos los protocolos sanitarios creados para la garantía de los derechos de los usuarios del servicio.

Lo anterior, con el objetivo de disminuir el número de víctimas de eventos adversos en procedimientos estéticos; para esto se debe tener en cuenta que la vida, la salud, la integridad física y psíquica de las personas como usuarios del servicio médico-sanitario, son "valores que trascienden de los meros intereses factibles de autorregulación negocial, y que se sitúan en el ámbito que el derecho reconoce al orden público". ${ }^{37}$

Existen víctimas diferentes al paciente a quien el prestador médico estético le puede causar daño; se han considerado como víctimas del evento adverso al "cónyuge, compañero o compañera permanente, y familiar en primer grado de consanguinidad, primero civil" ${ }^{38}$ del usuario de procedimientos estéticos; así las cosas, también será determinada víctima a la persona que considere y pruebe que padeció daños de manera indirecta o por rebote. ${ }^{39}$

Los familiares y los cónyuges o compañero (a) permanente cuando se establecen como víctimas, se erigen como beneficiarios de la póliza de responsabilidad civil para médicos e instituciones que realizan procedimientos estéticos; son catalogadas como víctimas por su condición de "afecto, solidaridad y de respeto, bien sea en razón de vínculos jurídicos o fácticos". ${ }^{40}$ Perjudicados a quienes el monto de la indemnización se ajustará dependiendo del grado de consanguinidad o proximidad con el sujeto víctima del daño causado en el ejercicio médico estético.

31 Cfr. OLANO GARCí, Op. Cit., pp. 360 y ss. Cfr. TAMAYO JARAMILLO, Javier.Tratado de responsabilidad civil. Tomo I y II. Bogotá: Editorial Legis S.A. 20 I0. Pp. 39 y ss. Cfr. QUINTERO NAVAS, Gustavo. La construcción de la responsabilidad del Estado en Colombia: entre la dualidad de jurisdicciones y la dualidad juridica. Bogotá: Universidad de Los Andes. 2009.

32 OLANO GARCÍA, Hernán Alejandro. Op.cit. El articulo 90 de la Constitución Política colombiana señala que "El Estado responderá patrimonialmente por los daños antijuridicos que le sean imputables, causados por la acción o la omisión de las autoridades públicas. En el evento de ser condenado el Estado a la reparación patrimonial de uno de tales daños, que haya sido consecuencia de la conducta dolosa o gravemente culposa de un agente suyo, aquél deberá repetir contra éste."

33 Corte Constitucional de Colombia, sentencia T-597 de 200I, Rodrigo Escobar Gil.

34 "Cirugia plástica de la mama encaminada a modificar su forma o tamaño". En: Diccionario de Medicina. España: Editorial Complutense.200।.p. 497.

35 Corte Constitucional de Colombia, sentencia T-597 de 200I, Rodrigo Escobar Gil.

36 TRIGO REPRESAS, STIGLITZ S. Op. cit. p. 26

37 Ibid. p. 26

38 Corte Constitucional de Colombia, sentencia C-370 de 2006, M.P. Manuel José Cepeda Espinosa, Jaime Córdoba Triviño, Rodrigo Escobar Gil, Marco Gerardo Monroy Cabra, Álvaro Tafur Galvis, Clara Inés Vargas Hernández.

39 Entiéndase perjudicados por rebote y perjudicados indirectos como lo mismo.

40 Cfr. Corte Constitucional de Colombia, sentencia C-029 de 2009, expediente D-7290, M.P. Rodrigo Escobar Gil. 
Las disposiciones normativas ${ }^{41}$ consagran que la víctima, causahabientes o perjudicados indirectos de un procedimiento de liposucción por ejemplo, pueden acudir a los despachos judiciales con el fin de buscar la protección y posterior reparación integral de los perjuicios causados por el tomador asegurado de la póliza; tomador que puede ser el médico estético experto en liposucción, quien procede a "retirar o succionar, como lo indica su nombre, el tejido graso profundo, que junto al tejido graso superficial da lugar a desproporciones corporales o lipodistrofias". ${ }^{+2}$

Cuando un usuario del servicio médico estético es víctima, tiene derecho a la reparación ${ }^{43}$ integral por los perjuicios ocasionados por el prestador en salud. Para ello, el Estado debe tomar las medidas pertinentes para asistir a las víctimas e impedir la vulneración de los derechos fundamentales ${ }^{4+}$ transgredidos, en este caso como consecuencia de una mala praxis médica estética por ejemplo.

Derechos fundamentales que pueden ser conculcados cuando un usuario del servicio de cirugía estética es víctima del hecho médico-sanitario dañoso, porque el galeno no dispuso del tiempo suficiente para el diagnóstico, auscultación y tratamiento en su requerimiento estético; si se ocasiona un evento adverso, se está vulnerando igualmente el derecho a la salud del paciente, por la imprudencia e inobservancia de los protocolos establecidos para procedimientos estéticos, o porque el prestador en salud, se reitera, apresure la emisión de un diagnóstico sin el "diálogo necesario entre el médico y el enfermo" 45 o usuario de los servicios del cirujano plástico con fines estéticos.

\section{El seguro de responsabilidad civil y su incidencia en la in- demnización integral a la vícti- ma del daño médico estético}

La indemnización a que tiene derecho la víctima directa, sus causahabientes y/o perjudicados indirectos de un procedimiento médico estético, debe ser entendida como una compensación por los perjuicios ocasionados por el evento adverso; el pago de la indemnización corresponde en conjunto a la cancelación de los perjuicios tanto patrimoniales o materiales, como extrapatrimoniales o inmateriales causados a las víctimas directas e indirectas de los citados procedimientos. El principal propósito de la reparación integral a favor de la víctima del daño causado por los prestadores de los servicios médicos estéticos, es devolver todo a la situación anterior a la ejecución del daño ${ }^{46}$ sanitario. ${ }^{47}$

El prestador de los servicios estéticos o en su defecto el asegurador, debe indemnizar los perjuicios patrimoniales representados en el daño emergente y el lucro cesante, ocasionados a la usuaria del servicio de un procedimiento de vaginoplastia por ejemplo. Esta técnica "sirve para la reparación de los defectos vaginales quirúrgicos o congénitos". ${ }^{47} \mathrm{El}$ daño emergente lo conforman los gastos o erogaciones ocasionadas al usuario de los servicios cuando se presente un evento adverso, y el lucro cesante se genera por la imposibilidad de la víctima de percibir recursos económicos a consecuencia del daño. Este, producido por el incumplimiento de un contrato de servicios médicos estéticos, como “institución construida por el derecho para establecer relaciones negociales en general, como intercambio

41 Para los efectos de este escrito entiéndase disposiciones normativas, normas, reglas y principios como lo mismo. No obstante es importante aclarar que según lo señalado por Robert Alexy, las normas son de estructura genérica; éstas pueden ser normas que pueden ser principios y normas que pueden ser reglas. Cfr.ALEXY, Robert.Teoría de los Derechos Fundamentales. Madrid:Centro de Estudios Constitucionales. 1993.

42 RAFFALLI, Cristina. ¿Debo operarme?:Verdades, ventajas y riesgos de la cirugía plástica. Venezuela: Editorial CEC. 1999. p. 66

43 Corte Constitucional de Colombia, sentencia C-370 de 2006, M.P. Manuel Cepeda Espinosa, Jaime Córdoba Triviño, Rodrigo Escobar Gil, Marco Gerardo Monroy Cabra, Alvaro Tafur Galvis, Clara Inés Vergas Hernández.

44 Corte Constitucional de Colombia, sentencia T-388 de 2002. M.P. Rodrigo Escobar Gil.

45 MOSSET ITURRASPE, Jorge, Responsabilidad por daños. Buenos Aires:Ediar. | 971, t. I, pp. 3 I-32. El autor hace la siguiente reflexión:“la mecanización determina una atención en serie de los usuarios de los servicios sanitarios que generan, sobre la base de análisis, radiografías y estudios a cargo de terceros que hacen que se resista al diálogo necesario entre el médico y el enfermo."

46 Congreso de la República de Colombia, Ley 975 de 2005.Art. 8. Diario Oficial No. 45.980 de 25 de julio de 2005.

47 KOTCHER FULLER, Joanna; et al. Instrumentación quirúrgica: teoría, técnica y procedimientos. México: Editorial Medica Internacional. 2008 . p.605 
de bienes y servicios, de tal modo que mínimamente posean una regulación efectiva." 48

Dentro del pago de los perjuicios extrapatrimoniales indicados antes, los cuales deben estar cubiertos en la póliza de responsabilidad civil para cirujanos plásticos estéticos, se encuentran los perjuicios morales, psicológicos, fisiológicos y los perjuicios a la vida de relación ${ }^{49}$; perjuicios que deben ser reparados de forma integral en favor del paciente, sus causahabientes y perjudicados indirectos por parte del prestador causante del evento adverso. Además de la reparación integral solicitada por el perjudicado, el demanda del prestador del servicio el respeto por su dignidad, libertad y autonomía ${ }^{50}$, aunque "la idea se centra no ya en castigar o en sancionar al autor de la conducta antijurídica, sino en la necesidad de que el daño deba ser reparado". ${ }^{51}$

El daño moral, o para efectos de cobertura de los perjuicios extrapatrimoniales en el seguro de responsabilidad civil, es más técnico hacer referencia al perjuicio mo$\mathrm{ral}^{52}$, ocasionado a la víctima quien sufre una aflicción o padecimiento producto de una lesión galénica por ejemplo; este perjuicio debe ser reparado en forma económica por cuanto se está lesionando o alterando su integridad de manera sistémica. Por ende, percibir una suma de dinero como consecuencia del evento adverso generado, es un derecho patrimonial iusfundamental, cuyo objetivo es atenuar el hecho ilegítimo soportado por el paciente, por la actuación culposa del galeno o de la institución en salud.

En el marco de la reparación integral a que están obligados los profesionales en procedimientos estéticos que ocasionen perjuicios al paciente, se ha enfatizado que además de la reparación pecuniaria de los perjuicios, se debe velar por la protección a los derechos a la verdad y a la justicia. Así, se debe garantizar "el derecho de toda persona para acceder a la administración de justicia". ${ }^{53}$ Esta, a la cual el usuario de los servicios de procedimientos estéticos, sus causahabientes y los perjudicados indirectos, tienen derecho y la cual está a cargo del Estado quien sanciona, por medio de sus operadores judiciales, por las conductas dañosas causantes de perjuicios a las víctimas de procedimientos de abdominoplastia por ejemplo; constituido éste como "una cirugía cosmética importante, que remueve el exceso de grasa de la pared abdominal." 54

La reparación de los perjuicios causados por particulares o el Estado debe ser integral, tal como lo establece la Declaración Universal de los Derechos Humanos, que expresa que toda persona y su familia, tienen derecho a un nivel de vida adecuado que le asegure la asistencia médica, salud y bienestar ${ }^{55}$; este último puede ser obtenido siempre que la reparación del daño generado por profesionales de medicina estética sea integral. Por ello el seguro se instituye como una "herramienta eficaz y de fundamental importancia en favor de las víctimas de la actividad dañosa" ${ }^{56}$

48 GHERSI, Carlos Alberto. Op. Cit. Pp.9, 15

49 Cfr.TAMAYO JARAMILLO, Javier.Op. cit. Cfr. HENAO PEREZ, Juan Carlos. El daño. Análisis comparativo de la responsabilidad extracontractual del Estado en el derecho colombiano y francés. Bogotá; Universidad Externado de Colombia. 2007. Cfr. DIAZ-GRANADOS ORTIZ, Juan Manuel. El Seguro de la Responsabilidad. Bogotá: Editorial Universidad del Rosario, 2006, pp. 105 y ss.

50 RUIZ OREJUELA, Wilson, Responsabilidad médica estatal. Bogotá: Ecoe Ediciones. 2004. p. 65.

5I WEINGARTEN, Celia, Cláusulas abusivas o la inconstitucionalidad de la ley de leasing. En: Cláusulas Abusivas 3, Nulidad e ineficacia; Director Carlos A. Ghersi. Buenos Aires: Editorial Juris. 200I. p. 146.

52 Consejo de Estado de Colombia, Sala de lo Contencioso Administrativo, Sección Tercera, C.P., Ruth Stella Correa Palacio, exp. I8.433, 3 de febrero de 2010. En cuanto al dolor moral el Consejo de Estado ha señalado lo siguiente: (...) En lo ateniente con el dolor moral por las lesiones graves, se ha precisado respecto a la víctima, que basta que demuestre la gravedad de la lesión; en lo que atañe con las victimas indirectas, se ha dicho que es necesario que se demuestren dos hechos: la lesión grave y el parentesco o vinculo de afecto; de la prueba de estos dos hechos se infiere judicialmente el dolor moral." Cfr. Consejo de Estado de Colombia, Sección Tercera, Sala de lo Contencioso Administrativo, sentencia 7449 del 26 de febrero de 1993 Citado por Consejo de Estado, Sección Tercera, Sala de lo Contencioso Administrativo, sentencia del 02 de mayo de 2002, exp. I3477, C.P. María Elena Giraldo Gómez.

53 OLANO GARCÍA, Hernán Alejandro.Op. cit. Artículo 229 C.P. de Colombia.

54 CHAPUNOFF, Eduardo. La obesidad mórbida. Estados Unidos: Ediciones Xlibris. 2010.p.235

55 Declaración Universal De Los Derecho Humanos. párrafo I, art. 25 Disponible en: http://www.un.org/es/documents/udhr/ recuperado: I 0/04/20I2.

56 GIMENEZ, Jorge Osvaldo. La cláusula claims made en el seguro de responsabilidad civil. En: Cláusulas Abusivas 3, Nulidad e ineficacia; Director Carlos A. Ghersi. Buenos Aires: Editorial Juris. 2001. p. 25. 
El principio de reparación integral ${ }^{57}$ impone la obligación al operador judicial de establecer una justa y correcta medición del daño ocasionado, con fundamento en principios constitucionales como la equidad para el resarcimiento o indemnización plena, sin que ésta se entienda como "un enriquecimiento injustificado a la víctima". ${ }^{58}$

A la responsabilidad contractual ${ }^{59}$ derivada del incumplimiento de un procedimiento estético, se le aplica lo atinente a la carga de la prueba correspondiéndole ésta a dicho prestador por tratarse de una obligación por resultado, donde el importe de la prima ${ }^{60}$ o precio del seguro es mayor; algunos fallos proferidos por la autoridad competente, se adhieren a la división de las obligaciones a cargo del prestador sanitario, señalando lo siguiente:

\section{"La obligación asumida por el médico frente al} paciente es una típica obligación de "medio" por contraposición a la de "resultado", ya que el profesional no se compromete a curar al enfermo sino solamente a poner su ciencia y diligencia con vista a la obtención de ese resultado". ${ }^{61}$ "La obligación médica frente al paciente es por regla general, de medios y excepcionalmente, de resultado, puesto que el profesional no se compromete a curar al paciente sino a observar una conducta (asistencia médica) que razonablemente conducirá a un resultado, cuya obtención no se garantiza". ${ }^{62}$

En este sentido la responsabilidad contractual derivada de una obligación de medio a cargo del operador en salud, puede ser producto del incumplimiento de un contrato de prestación de servicios médico-sanitarios ${ }^{63}$, donde el agente en salud debe demostrar que actuó conforme a los parámetros descritos en la prestación, con el propósito de eximirse de su responsabilidad. Indemnización a cancelar por parte de la compañía aseguradora de acuerdo con los límites de indemnización pactados.

Al no celebrarse un acto jurídico bilateral entre el usuario de los servicios médicos estéticos y el agente prestador de los mismos, se genera una responsabilidad civil extracontractual, al presentarse el daño. Es importante señalar que la obligación del médico está catalogada como obligación de medios "salvo pacto en contrario, de suyo válido, quien desplegará los medios, pero sin poder asegurar un específico logro". ${ }^{64}$ Así, el galeno dedicado a la realización de procedimientos estéticos debe velar en el desarrollo del contrato

57 Congreso de la República de Colombia, Ley 446 de 1998.Articulo 16. Diario Oficial No.43.335 de 8 de julio de | 998 "Por la cual se adoptan como legislación permanente algunas normas del Decreto 265I de 199I, se modifican algunas del Código de Procedimiento Civil, se derogan otras de la Ley 23 de 1991 y del Decreto 2279 de 1989, se modifican y expiden normas del Código Contencioso Administrativo y se dictan otras disposiciones sobre descongestión, eficiencia y acceso a la justicia".

58 Consejo de Estado de Colombia, Sala de lo Contencioso Administrativo, Sección Tercera, C.P., Ruth Stella Correa Palacio, exp. 18.433, 3 de febrero de 2010

59 "La responsabilidad contractual es imputada al deudor (...) por dolo suyo en el cumplimiento de la obligación" y "cuando por culpa propia ha dejado de cumplirla." En la responsabilidad extracontractual el art. 1382 del Código francés señala que "Todo el que ejecuta un hecho, que por su culpa o negligencia ocasiona un daño a otro, está obligado a la reparación del perjuicio". Cfr. LÓPEZ, Roberto, Temas de Responsabilidad Civil: Contractual y extra contractual. Buenos Aires: Ediciones Ciudad Argentina. 1995.p. 12

60 La prima a favor del asegurador, depende del riesgo trasladado. En este orden de ideas, "Desde la compañia de seguros, se espera la obtención de una tasa de beneficio, por la asunción del riesgo, que puede maximizarse al no acaecer el siniestro: para el tomador, controlar ciertos $y$ determinados riesgos económicamente, es decir, evitar afrontarlos de manera individual y a su entero costo (...), y para el beneficiario, asegurar la indemnización, ya que la asume la compañía de seguros (seguridad económica y jurídica)" Cfr. GHERSI, Carlos Alberto. Op. cit. p. 3

6I Cámara Federal Argentina, sentencia del 5 de noviembre de I98I. En:JARAMILLOJ., Carlos Ignacio. Responsabilidad Civil Médica:la relación médico-paciente, análisis doctrinal y jurisprudencial. Bogotá: Pontificia Universidad Javeriana. 20।0. p. 355

62 lbíd. p. 355

63 Dentro de la responsabilidad médica en los contratos el estatuto del consumidor en Colombia establece esta acotación de las cláusulas abusivas: "artículo 42. concepto y prohibición. Son cláusulas abusivas aquellas que producen un desequilibrio injustificado en perjuicio del consumidor y las que, en las mismas condiciones, afecten el tiempo, modo o lugar en que el consumidor puede ejercer sus derechos. Para establecer la naturaleza y magnitud del desequilibrio, serán relevantes todas las condiciones particulares de la transacción particular que se analiza. Los productores y proveedores no podrán incluir cláusulas abusivas en los contratos celebrados con los consumidores, En caso de ser incluidas serán ineficaces de pleno derecho." Cfr. Congreso de la República de Colombia, Ley 1480 de 20I I.Articulo 42. Diario Oficial No. 48.220 de 12 de octubre de 201 I "Por medio de la cual se expide el Estatuto del Consumidor y se dictan otras disposiciones".

64 JARAMILLO J., Carlos Ignacio. La culpa y la carga de la prueba en el campo de la responsabilidad médica. Bogotá: Ibáñez .2010.p. I 0 
médico, por una prestación eficiente del servicio y su actuar debe estar enmarcado en la diligencia ${ }^{65}$, porque de lo contrario incurre en responsabilidad que puede ser objeto de cobertura en la póliza.

La responsabilidad del médico estético, es aquella en la cual incurre dicho profesional, cuando su actuar es culposo en la actividad desarrollada, "es decir, en tratar de curar al paciente" ${ }^{\prime 66}$ o realizar un procedimiento para lo cual fue contratado. Por regla general, como se ha venido señalando, las obligaciones del prestador en salud son de medio, no obstante, "son de resultado, como sucede con la cirugía plástica cuando aquella tiene por objeto un fin puramente estético" ${ }^{\text {67 }}$ Un ejemplo de este último caso, es "el levantamiento de las mamas o mastopexia (el cual) es un procedimiento autónomo o un gesto quirúrgico complementario habitual de otras cirugías. Dependiendo del tamaño previo se podrá o no hacer que ambas mamas se levanten y se aproximen".68 En este caso, el importe de la prima a favor del asegurador es más cuantiosa para quienes desarrollan estas actividades, por cuanto en el evento de presentarse una eventual responsabilidad, le corresponde al abogado asignado al cirujano plástico estético, desplegar todas las pruebas necesarias con el objetivo de salvar la responsabilidad de su cliente.
En suma, la responsabilidad médico-sanitaria ${ }^{69}$ contractual o extracontractual en que puede incurrir el médico estético puede ser objeto de cobertura en el seguro de responsabilidad civil para dicho profesional y ésta se produce como consecuencia del incumplimiento de las obligaciones a cargo del deudor que causa perjuicios al paciente, con la consecuente lesión "en su honor, crédito, afectos, creencias, etc".70

El ejercicio de la actividad médica estética es riesgoso porque se involucran los derechos del usuario del servicio, a la vida e integridad física y mental del paciente; no por ello a los daños generados en dicha actividad se les aplica la responsabilidad objetiva con presunción de ésta, sino el régimen subjetivo ${ }^{71}$ de responsabilidad, no obstante se utilicen instrumentos, aparatos o equipos médicos y demás procedimientos médicos estéticos, que generen riesgos para el paciente; se debe señalar que "el organismo del paciente está sometido a enormes riesgos por el simple hecho de la actividad del médico al efectuar el tratamiento"72 o un procedimiento estético.

Así, en algunas legislaciones no existen normas donde se pueda inferir el desplazamiento de la culpa "como eje del sistema de responsabilidad civil, por más que

65 Ibíd. p. 110

66 PARRA GUZMÁN, Mario Fernando. Responsabilidad Civil. Bogotá: Doctrina y Ley. 20 10.p.285

67 Ibid. P.285. En Latinoamérica están proliferando las clínicas dedicadas a procedimientos estéticos, las cuales realizan fuertes campañas publicitarias a los usuarios de estos servicios. Se ha señalado que "La actividad profesional y empresarial son en sí mismas actividades que engendran riesgos, y la publicidad de los bienes y servicios que realizan en una fase más de la cadena productiva, representa uno de los aspectos sobresalientes de esta y constituye la herramienta fundamental a partir de la cual se logra captar el mercado."

Cfr. LOVECHE, Graciela, Información y Publicidad del Servicio Médico. Editorial Astrea: Buenos Aires. 2004. P.202

68 BLEJER, Carlos. Lesiones por procedimientos estéticos: criterios médicos y jurisprudenciales.Argentina: Editorial Juris. 2006. p. I89

69 Es preciso señalar, que la "responsabilidad médico-hospitalaria se encuentra asentada sobre la base de un criterio culpabilista en el que mal haría la jurisprudencia administrativa en tildar la medicina como una actividad riesgosa, no obstante, se insiste, existen varios escenarios en los que es posible predicar la existencia de un régimen objetivo. A modo ilustrativo se pueden destacar los siguientes supuestos: i) en virtud de la peligrosidad de la cosa, del procedimiento o el tratamiento empleado, lo siempre y cuando la herramienta riesgosa cause el daño de manera directa o por ella misma, pues si la lesión es producto de una ejecución irregular del acto médico, aunque medie un instrumento que represente peligro o riesgo, el caso específico está regido por la responsabilidad subjetiva o culposa, ii) cuando respecto de un medicamento, tratamiento o procedimiento que implica o conlleva un progreso en la ciencia y, por lo tanto, se considera novedoso, se desconocen las consecuencias o secuelas a largo plazo del mismo, iii) cuando en el acto médico se emplean químicos o sustancias peligrosas (...) Cfr. Consejo de Estado de Colombia, Sección Tercera, Sala de lo Contencioso Administrativo, sentencia del 03 de mayo de 2007, exp. I 6696, C.P. Enrique Gil Botero.

70 PÉREZ VIVES, Alvaro. Teoría general de las obligaciones, Tomo II. Bogotá: Editorial Temis. 1968. P.245

71 Algunos autores expertos en el tema de la responsabilidad civil señalan que la responsabilidad civil del médico es subjetiva"siempre y cuando exista un seguro de responsabilidad civil obligatoria de forma tal que no sea el médico o la entidad hospitalaria que asuma el costo de las indemnizaciones". Cfr. TAMAYO JARAMILLO. Javier. Sobre la prueba de la culpa médica: En derecho civil y administrativo. Bogotá: Diké. 20I I. Pp. 99-I00. GHERSI; Carlos, Universidad de Buenos Aires, módulo de Derecho y Salud, Doctorado en Derecho, clase magistral, Buenos Aires, enero 2012.

72 TAMAYO JARAMILLO, Javier. Op. cit., pp. 1068 y ss. 
interpretativamente algunos tribunales hayan ampliado desmesuradamente el ámbito de la responsabilidad objetiva". ${ }^{73}$

Como se viene señalando, las actividades del prestador en salud que se consideran riesgosas como el suministro de medicamentos, la realización de terapias o pruebas de esfuerzo para diagnosticar cualquier inconveniente cardíaco, el uso de gadolinio como medio de contraste en los procedimientos de resonancia nuclear magnética, la toma de muestras de sangre en un laboratorio clínico y los procedimientos de cirugía plástica estética, entre otras. El asegurador cobrará el importe de la prima al asegurado, de acuerdo al riesgo trasladado por él.

Riesgo que surge como producto de los daños causados por las denominadas actividades peligrosas, donde se pueden incumplir las obligaciones de seguridad a cargo, en este caso del prestador sanitario y cuyo principal propósito es el de "conservar el equilibrio estable de los derechos y de los intereses de las personas en su vida de comunidad". ${ }^{74}$ Personas que se han sometido al conocimiento y pericia de un profesional médico estético, para la conservación de su derecho a la vida y como consecuencia a la salud. Las obligaciones de seguridad y garantía son impuestas a los prestadores médicos estéticos y a las instituciones en salud, y tienen comoobjeto la protección a los usuarios de estos servicios, a través de la prevención general $^{75}$, asícomola sanción por los daños causados por el incumplimiento de las obligaciones.

Como se ha venido señalando, el médico estético puede dentro de la ejecución de procedimientos propios de su profesión incurrir en conductas que ocasionen daños al usuario de sus servicios. Ante esta situación el estado debe "asegurar a las víctimas de esas conductas el acceso a recursos eficaces que reparen el daño infligido ${ }^{76}$ producto de un hecho humano y/o el ente prestador sanitario". El operador judicial sancionará al actor de ese evento adverso, bajo el fundamento de que la medicina es "una profesión que tiene como fin cuidar de la salud del hombre y propender por la prevención de las enfermedades, el perfeccionamiento de la especie humana y el mejoramiento de los patrones de vida de la colectividad, sin distingos de nacionalidad ni de orden económico-social, racial, político y religioso". ${ }^{77}$

Una de las actividades profesionales más expuestas a generar daños a las personas es la medicina estética y afines. Inicialmente, se estimaba que el médico no podía ser considerado responsable, pues se decía que no incurrían en culpa. Esta posición cambió con el tiempo y hoy en día existen claros principios de responsabilidad, lo cual coloca a profesionales e instituciones de salud en la necesidad de proteger su patrimonio vía seguros. $^{78}$

Como resultado de los daños ocasionados por los prestadores de los servicios en salud a los usuarios del mismo, se presentan cada día un gran número de procesos judiciales contra médicos estéticos, enfermeros o paramédicos por ejemplo, por mala praxis en su actividad. Las decisiones finales de los tribunales de justicia que condenan a los profesionales médicos en altas cuantías $^{79}$, llevan a establecer que la garantía del

73 LÓPEZ MESA, Marcelo, en:TRIGO REPRESAS- LÓPEZ MESA, “Tratado de la responsabilidad civil”, cit. T.I, pp. 5 I y ss. Citado por LOPEZ Marcelo. Elementos de la Responsabilidad Civil. Medellín: Editorial Biblioteca Jurídica DIKE. 2009. p. 460."La responsabilidad por culpa tuvo siempre, y aún conserva, sobre dichas responsabilidades objetivas una ventaja cierta: el art. I 109 del Código Civil argentino, al igual que el art. 1902 del Código Civil español y los arts. I 382 y I 383 del Código de Napoleón constituye la expresión de un principio general: la culpa se aplica a todos los sectores del derecho privado; en cambio, no existe una disposición comparable consagrando un principio general de responsabilidad sin culpa o por riesgo creado". Cfr. RADÉ, c. Réflexions..., ct., p. 315. Citado por LOPEZ Marcelo, Op. Cit p.466

74 SANTOS BALLESTEROS, Jorge. Instituciones de responsabilidad civil, T. I. Bogotá: Pontificia Universidad Javeriana. 1996. p. 13

75 CALABRESI, Guido. "Some thoughts on risk distribution and the Law of Torts", Yale Law Journal. 1961. N 70 1961.pp. 83 y ss.

76 Corte Constitucional de Colombia, sentencia C-370 de 2006, M.P. Manuel José Cepeda Espinosa, Jaime Córdoba Triviño, Rodrigo Escoba Gil, Marco Gerardo Monroy Cara, Alvaro Tafur Galvis, Clara Inés Vargas Hernández.

77 Congreso de la República de Colombia, Ley 23 de 1981. Diario Oficial No. 35.7। I, del 27 de febrero de 1981 "Por lo cual se dictan normas en materia de ética médica".

78 DIAZ-GRANADOS ORTIZ. Op. cit., p. 431

79 Cfr. Revista Íbero-Latinoamericana de Seguros. N. 16. Bogotá: Pontificia Universidad Javeriana. 200I. Así mismo, pueden accionar legalmente en calidad de demandantes "los familiares o personas a cargo que tengan relación con la víctima directa y las personas que hayan sufrido daños": GONZÁLEZ NAVARRO, Luis Antonio. Sistema de juzgamiento penal acusatorio. Bogotá: Editorial Leyer. 2005. p. 1098 
pago de la indemnización a cargo de los prestadores la constituye la suscripción de una póliza de responsabilidad civil para quienes realicen procedimientos estéticos.

Este seguro ${ }^{80}$ es un acto jurídico mediante el cual el recurso humano operador en salud y el ente sanitario público o privado, trasladan el riesgo inherente a su actividad médica estética a un asegurador a cambio del pago de una prima ${ }^{81}$; el importe de ésta dependerá de factores tales como el nivel de riesgo de la actividad médico-asistencial que realiza el tomador asegurado, de los límites de indemnización establecidos, de las garantías ${ }^{82}$ y de las exclusiones dispuestas en la póliza.

Cuando se hace alusión al seguro de responsabilidad civil, se toma por un lado la responsabilidad misma y por otra el contrato de seguro patrimonial de responsabilidad civil, que en conjunto involucran al asegurador, el asegurado y la víctima usuaria de los servicios de procedimientos estéticos. Sujetos que no escapan de una situación contenciosa en razón de las diferentes situaciones que se pueden originar a partir de la celebración de un acto jurídico.

Los asegurados como deudores de la indemnización a favor del paciente buscan descargar su obligación suscribiendo una póliza de responsabilidad civil. De otro lado se encuentra el asegurador que tiende a minimizar los riesgos trasladados y hasta llega a negar la obligación de indemnización, poniendo en riesgo la reparación integral de la víctima; por último las víctimas como acreedores y beneficiarios de la póliza, cuyo objetivo es reclamar esa indemnización en el menor tiempo posible..$^{83}$

El seguro de responsabilidad civil puede ser suscrito por personas naturales o jurídicas que ejercen actividades médicas estéticas, con el objetivo de desagraviar y satisfacer al ofendido. ${ }^{84}$ El beneficio para el profesional de la salud que suscribe una póliza es evitar que su patrimonio se vea afectado como consecuencia de la decisión judicial de reparar de forma integral a la víctima del hecho médicosanitario dañoso, de sus causahabientes o terceros perjudicados, aspecto que será investigado a fondo y publicado en un escrito diferente; así, con la póliza de seguros la víctima del hecho médico-sanitario dañoso puede "obtener el resarcimiento sin temor por la eventual insolvencia del asegurado" en favor del perjudicado. ${ }^{85}$

Es factible que el resarcimiento a la víctima no se presente, toda vez que en un proceso judicial se puede ordenar el pago de la indemnización a cargo del médico cirujano estético, pero si éste carece de recursos económicos no se garantiza la reparación a las víctimas del daño; por ende, se puede establecer la verdad y la justicia en un proceso ante el hecho dañoso, pero no la reparación integral a las víctimas del mismo.

Hecho dañoso ocasionado a los usuarios del servicio en salud en las actividades médicas estéticas, que

80 (...) la responsabilidad y el seguro son instituciones diferentes pero al tiempo estrechamente concurrentes. Se trata de dos fenómenos distantes en su contenido, fundamento, instrumentación y finalidad, pero que con el tiempo ha podido combinarse hasta casi convertirse en un "binomio indisoluble". El seguro es una cautela de quien quiere garantizarse contra el riesgo, lo que es un criterio económico y no moral; la responsabilidad es una sanción patrimonial de quien incurre en culpa, lo que es un criterio moral y no económico. Una y otro son técnicas de reparación del daño, pero mientras la responsabilidad, por regla general, pretende hacer asumir a una persona la carga del daño; el seguro pretende repartir dicha carga lo más que se pueda, a fin de que se torne lo más ligera posible para aquellos que tienen que soportarla. Cfr., FERNÁNDEZ MUÑOZ, Mónica Lucia. La responsabilidad médica: Problemas actuales. Bogotá: Ibáñez. 2008. Pp 266 y 267.

81 “(...) concebida, según lo expuesto, como el precio del seguro, la prestación que debe pagar el asegurado a trueque de la promesa de una contraprestación eventual (la indemnización de la pérdida o daño o el pago de la suma asegurada en el caso del siniestro), la prima esconde un contenido económico íntimamente vinculado a su significación técnica y a su naturaleza jurídica" En: OSSA G, J. Efrén. Teoría general del seguro. Bogotá: Editorial TEMIS. I998. pp. I7I y ss.

82 En el siglo XIX la garantía de calidad tenía una naturaleza esencialmente contractual, pues los jueces la consideraron implícita en los contratos de compraventa' Cfr.WOOLCOTT Olenka. La responsabilidad Del Productor. Bogotá: Ibáñez. 2007. p.50

83 FERNANDEZ MUÑOZ, Mónica Lucia. Op. Cit. P.292

84 La Real Academia Española define la reparación como el desagravio y la satisfacción al ofendido, en este caso del paciente. Cfr. www.rae.es recuperado: $23 / 04 / 2012$.

85 PENNEAU, Jean. Faute et erreur en matiere de responsabilité médicale. Paris. 1973, pp. 247 y siguientes. En:TRIGO REPRESAS. STIGLITZ S. Op, cit.,p. 32. 
pueden generar responsabilidad y están enmarcadas en el área del derecho que regula el resarcimiento del daño producido ${ }^{86}$, por ejemplo por el incumplimiento de un deber de cuidado en un procedimiento de fontoplastia; esta, "técnica quirúrgica de rejuvenecimiento en la que se tratan la frente y las cejas, que con el paso del tiempo pueden llegar a caer sobre los párpados ayuda a corregir las arrugas transversas de la frente, las del entrecejo y las de la porción superior del dorso nasal". 87

Esta situación impone al profesional médico estético el pago de indemnizaciones, sin perjuicio de otras sanciones $^{88}$ que se pueden asignar en su contra y que serían pagadas por el asegurador, en el evento de haberse suscrito un seguro de responsabilidad civil. Indemnización sufragada por la compañía aseguradora, de acuerdo con los límites y coberturas amparadas dentro del contrato.

La suscripción de la póliza de responsabilidad civil implica que los prestadores médicos estéticos trasladan los riesgos propios del ejercicio de su profesión a una compañía aseguradora; como consecuencia, el prestador de estos servicios no auto-retiene los riesgos inherentes a su actividad, sino que propende por la protección de su patrimonio con la suscripción de dicha póliza. A la vez que protege su patrimonio, garantiza el pago de la indemnización integral a la víctima del daño en salud.
Así, se indican los principales propósitos de la suscripción de esta póliza de responsabilidad civil para prestadores sanitarios, en primer lugar el resarcimiento de los perjuicios causados al paciente, sus causahabientes y perjudicados indirectos, que se constituyen en beneficiarios de la indemnización a cargo del agente médico estético; además, con el seguro se trata de proteger el derecho al patrimonio ${ }^{89}$ que tiene el prestador de este servicio, el cual se vería afectado ante la ocurrencia de un evento adverso ${ }^{90}$, y la indemnización a su cargo, en favor del usuario de los servicios médicos perjudicado. Usuario instituido como beneficiario de la póliza e interviniente dentro del contrato de seguro y a quien se le pueden causar lesiones en un procedimiento de otoplastia por ejemplo. Procedimiento realizado para "corregir las deformidades de las orejas. Está indicada para defectos congénitos, orejas en asa u otros tipos de deformidades"."

Por consiguiente, las normas de responsabilidad médico-sanitaria y de seguros buscan la protección de los derechos de los usuarios del servicio de salud, por cuanto el coste $e^{92}$ de los eventos adversos provocados perjudica el patrimonio y el ejercicio profesional de los prestadores sanitarios, quienes se obligan a suscribir el seguro de responsabilidad civil.

El interés de proteger el patrimonio por parte de los profesionales y las instituciones de salud, se debe enfocar asímismo en la reparación integral de los daños

86 "Al iniciar este siglo la atención es orientada al resarcimiento de los daños personales causados por la negligencia, a través del reconocimiento de un deber de cuidado para evitarlos sin que venga en consideración que los mismos se produjeran dentro de un contexto contractual o no. Lo que contaba era mantener un cierto nivel de conducta". Cfr. WOOLCOTT Olenka. Op.cit. p. 36

87 Galán Ricardo. Castillo Ana Luz. Cirugías Estéticas: todo lo que usted necesita saber. Bogotá: Editorial Norma. 200 I.P.86

88 En la actualidad se encuentran vigentes en Colombia tres sistemas penales: el inquisitivo cuando se juzga congresistas, el mixto (Instrucción y juzgamientos) y el acusatorio regulado por la Ley 906 de 2004. Si un médico asegurado con una póliza de responsabilidad civil para prestadores en salud causa lesiones a un paciente en una intervención médica estética el día $\mathrm{I}^{\circ}$. de enero de 2005 (fecha en la que empezó a regir el nuevo sistema penal acusatorio en Bogotá), el sistema procesal a aplicar es el de tendencia acusatoria. El facultativo causante del delito debe dar aviso del hecho dañoso al asegurador para éste le asigne un abogado experto en Derecho Penal y Proceso Penal. Cfr. OSORIO ISAZA, Luis Camilo, LONDOÑO ALVAREZ, et.AI. Sistema PenalAcusatorio, Reflexiones jurídicas, económicas y sociales. Bogotá: Pontificia Universidad javeriana, 2005. Cfr. LOMBANA VILLALBA. Op. Cit. Pp. II 9 y ss.

89 Cuando se trata de un contrato cuyo beneficiario es el asegurado no se es personalmente del daño ocasionado a la víctima, sólo será deudor de la indemnización en razón de la obligación de garantía producto del contrato.Asi, uno de los propósitos del seguro de responsabilidad civil es evitar que el responsable del hecho ocasionado sea "arruinado en su patrimonio" como consecuencia de la deuda de responsabilidad que le es imputada. En: FERNÁNDEZ MUÑOZ, Mónica Lucia. Op. Cit. Pp. 296-297

90 Los prestadores médico-sanitarios tratar de evitar los eventos adversos "por el hecho de que cada uno, al conocer el riesgo de ser condenado si comete un daño, se esfuerza normalmente para actuar con prudencia”. Cfr. LE TOURNEAU. Op, cit., p.45

9I VALLEJO Jaime. Cirugía Plástica para Todos. Colombia. 201 I. p. 35

92 CALABRESI, Guido. Op.cit. p. 83 
causados a las víctimas de procedimientos estéticos..$^{93}$ Decisión que se materializa en la suscripción de la póliza de responsabilidad civil para prestadores del servicio en salud.

En desarrollo de lo descrito, el usuario del servicio de salud es el beneficiario del seguro de responsabilidad civil para prestadores médico-sanitarios que realizan procedimientos médicos estéticos, quien es reparado por la aseguradora de acuerdo con las condiciones de la póliza de seguro que se suscribió, los límites a la indemnización y las respectivas exclusiones. Adicionalmente los causahabientes y perjudicados indirectos o por rebote, pueden ser indemnizados por la compañía aseguradora por los daños causados por el prestador en salud ${ }^{94}$, lo cual garantiza la protección del derecho fundamental a la reparación integral de las víctimas de una mala praxis médica. Daños que se pueden causar al paciente en un procedimiento de blefaroplastia que "consiste en eliminar el exceso de piel del parpado superior y retirar las bolsas de grasa ubicadas en los parpados inferiores y en el ángulo interno de los parpados superiores". ${ }^{95}$

\section{Conclusiones}

Se encontró en la investigación bibliográfica realizada, que el usuario de los servicios de procedimientos de cirugía plástica estética puede sufrir daños como consecuencia de la relación contractual con el prestador en salud, ante la presencia de eventos adversos. Por este hecho, tanto el usuario de los servicios médicos estéticos como los causahabientes y perjudicados indirectos, pueden demandar la protección de sus derechos, incluido el de reparación integral catalogado como fundamental.

En la investigación se estableció que el derecho fundamental a la reparación integral a la víctima del daño médico estético no está garantizada; lo anterior, porque el patrimonio del prestador que respondería por el pago de la indemnización a favor de la víctima puede ser insuficiente o inexistente. Se llegó a determinar que la reparación integral de la víctima de un procedimiento médico estético, se puede garantizar siempre que el prestador en salud suscriba una póliza de responsabilidad civil para profesionales e instituciones sanitarias que realizan el citado procedimiento.

Se evidenció que la víctima del daño médico estético generador de perjuicios al paciente, sus causahabientes y perjudicados indirectos son los beneficiarios de la póliza de responsabilidad civil; este hecho garantizaría el derecho a la reparación integral de los perjuicios materiales e inmateriales causados al sujeto pasivo del daño.

En la investigación realizada se determinó que la póliza de responsabilidad civil debe contar con unos límites de indemnización y coberturas acordes con los riesgos generados en la prestación médica estética, con el objetivo de alcanzar una reparación integral a la víctima y por ende lograr reparar a la misma.

\section{Lecturas recomendadas}

Alexy R. Teoría de los derechos fundamentales. Madrid, España: Centro de Estudios Constitucionales; 1993.

Blejer C. Lesiones por procedimientos estéticos: criterios médicos y jurisprudenciales. Buenos Aires: Editorial Juris; 2006.

Calabresi G. Some thoughts on risk distribution and the Law of Torts. Yale Law J.1961; 70(4): 499-553.

Colombia. Congreso. Código Civil Colombiano. Bogotá: Leyer; 2012.

Colombia. Congreso. Ley 23 de 1981 (18 de febrero) por la cual se dictan normas en materia de ética médica. Publicada en el Diario Oficial No. 35.711, del 27 de febrero de 1981

Colombia. Congreso. Ley 446 de 1998 (Julio 7) por la cual se adoptan como legislación permanente algunas normas del Decreto 2651 de 1991, se modifican algunas del Código de Procedimiento Civil, se derogan otras de la Ley 23 de 1991 y del Decreto 2279 de 1989 , se modifican y expiden normas del Código Contencioso Administrativo y se dictan otras disposiciones sobre descongestión, eficiencia y acceso a la justicia. Publicado en Diario Oficial No. 43.335 de 8 de julio de 1998

Colombia. Congreso. Ley 975 de 2005 (Julio 25) por la cual se dictan disposiciones para la reincorporación de miembros de grupos armados organizados al margen de la ley, que contribuyan de manera efectiva a la consecución de la paz nacional y se dictan otras disposiciones para acuerdos humanitarios. Publicada Diario Oficial No. 45.980 de 25 de julio de 2005.

Colombia. Congreso. Ley 1480 de 2011 (Octubre 12) por medio de la cual se expide el Estatuto del Consumidor y se dictan otras disposiciones. Publicada Diario Oficial No. 48.220 de 12 de octubre de 2011 .

93 "La finalidad de protección de las victimas explica en gran medida el desarrollo prodigioso que ha tenido el seguro RC. Desarrollo que a su vez se debe a la toma de conciencia acerca de la importancia y la gravedad del riesgo de responsabilidad civil en el mundo moderno. Además, la ocurrencia de riesgos de accidentes, resultado del carácter peligroso de una gran numero de actividades, ha multiplicado las posibilidades de que sea puesta en tela de juicio la responsabilidad civil, incitando a que el legislador y la jurisprudencia pongan en marcha sistemas de responsabilidad mucho más estrictos, lo que a su vez conlleva a que los potenciales responsables se vean en la necesidad de contratar un seguro". Cfr. FERNÁNDEZ MUÑOZ, Mónica Lucia. Op.cit. p. 289

94 "Para corroborar con la seguridad jurídica por parte del Estado hacia el usuario el Sistema de Seguridad Social en Salud con fundamento en la equidad, fue creado para proveer de servicios de salud de igual calidad a todos los habitantes del territorio nacional, sin importar su capacidad de pago". Cfr. Congreso de la República de Colombia citado por GALINDO VACHA, Juan Carlos. Op. cit. p.69

95 VALLEJO Jaime, Cirugía Plástica para Todos. Colombia. 20II. P.31 
Chapunoff E. La obesidad mórbida. Washington: Ediciones Xlibris; 2010.

Díaz-Granados Ortiz JM. El Seguro de la responsabilidad. Bogotá: Editorial Universidad del Rosario; 2006.

Diccionario de Medicina. Madrid, España: Editorial Complutense; 2001

Fernández Muñoz ML. La responsabilidad médica: problemas actuales. Bogotá: Grupo Editorial Ibáñez; 2008.

Gala R, Castillo AL. Cirugías estéticas: todo lo que usted necesita saber. Bogotá: Edi-, torial Norma. 2001.

Galindo Vácha JC. La salud y su aseguramiento en Argentina, Chile Colombia y Espa= ña. Madrid: Editorial Fundación Mapfre;2011.

GhersiCA. Contrato de seguro. Buenos Aires: Editorial de Astrea; 2007.

Giménez JO. La cláusula claims made en el seguro de responsabilidad civil. En: Ghersi CA, director. Cláusulas abusivas 3, nulidad e ineficacia. Buenos Aires: Editorial Juris; 2001 .

González Navarro LA. Sistema de juzgamiento penal acusatorio. Bogotá: Editorial Leyer; 2005.

HenaoPérez JC. El daño. Análisis comparativo de la responsabilidad extracontractual del Estado en Derecho colombiano y francés. Bogotá: Universidad externado de Colombia; 2007.

Jaramillo Cl. Responsabilidad civil médica: la relación médico-paciente, análisis doctrinal y jurisprudencial. Bogotá: Universidad Pontificia Javeriana; 2010.

Jaramillo CI.La culpa y la carga de la prueba en el campo de la responsabilidad médica. Bogotá: Grupo EditorialIbáñez; 2010

O’Toole M, directora,KlajnDS, traductora. Diccionario enciclopédico de enfermería Buenos Aires: Médica Panamericana; 1996.

Le Tourneau P. La responsabilidad civil profesional. Bogotá: Editorial Legis. 2006.

Lombana VIllalba J. Derecho penal y responsabilidad médica, 3aed. Medellín: Editorial Diké; 2007

López Oliva JO. El derecho fundamental a la salud. Revista laboratorio actual. 2007 oct.; 40: 36

López M. Elementos de la responsabilidad civil. Medellín: Biblioteca Jurídica DIKE; 2009

López R. Temas de responsabilidad civil: contractual y extra contractual. Buenos Aires: Ediciones Ciudad Argentina; 1995.

LorenzettiRL. Responsabilidad profesional. Buenos Aires: Editorial Abeledo Perrot; 1995 .

Lovece G. Información y publicidad del servicio médico. Buenos Aires: Editorial As trea; 2004.

Mosset Iturraspe J. Responsabilidad por daños. Buenos Aires: Ediar; 1971. Tomo 1

Olano GarcíaHA. Constitución política de Colombia. Bogotá: Doctrina y Ley; 2011.

Osorio IsazaLC, Londoño Álvarez, et. al. Sistema penal acusatorio: reflexiones jurídicas, económicas y sociales. Bogotá: Pontificia Universidad Javeriana; 2005.

OssaJE. Teoría general del seguro. Bogotá: Editorial TEMIS; 1998.

Parra GuzmánMF. Responsabilidad civil. Bogotá: Doctrina y Ley; 2010.

Pérez VivesA. Teoría general de las obligaciones. Bogotá: Editorial Temis; 1968. Tomo 2.

Quintero Navas G. La construcción de la responsabilidad del Estado en Colombia: entre la dualidad de jurisdicciones y la dualidad jurídica. Bogotá: Universidad de los Andes; 2009.

Raffalli C. ¿Debo operarme?: verdades, ventajas y riesgos de la cirugía plástica. Caracas: Editorial CEC; 1999

Colombia. Ministerio de Protección Social. Resolución número 1446 del 8 de mayo de 2006 por la cual se define el Sistema de Información para la Calidad y se adoptan los indicadores de monitoria del Sistema Obligatorio de Garantía de Calidad de la Atención en Salud.

Díaz Granados J. El seguro de responsabilidad civil. Revista Íbero-Latinoamericana de Seguros. 2001; 16

Ruiz Orejuela W. Responsabilidad médica estatal. Bogotá: Ecoe Ediciones; 2004.

Santos BallesterosJ. Instituciones de responsabilidad civil. Bogotá: Pontificia Universidad Javeriana; 1996. Tomo 1.

Tamayo Jaramillo J. Tratado de responsabilidad civil. Bogotá: Editorial Legis; 2010. Tomo I y II

Tamayo Jaramillo J. Sobre la prueba de la culpa médica en derecho civil y administrativo, análisis doctrinal y jurisprudencial. Bogotá: Biblioteca jurídica Diké; 2011.

Trigo Represas FA, Stiglitz S. El seguro contra la responsabilidad civil profesional de médico. Buenos Aires: Editorial Astrea; 1983.

WeingartenC. Cláusulas abusivas o la inconstitucionalidad de la ley de leasing. En Ghersi CA, director. Cláusulas abusivas 3: nulidad e ineficacia. Buenos Aires Editorial Juris; 2001

Woolcott O. La responsabilidad del productor.Bogotá:Ibañez; 2007.

Yepes Restrepo S.La responsabilidad civil médica. Medellín Diké; 1992.

Vallejo J. Cirugía estética para todos. Bogotá: Jaime Vallejo; 2011.

\section{Webgrafia}

BarberoGutiérrezJ. El derecho del paciente a la información: el arte de comunicar. An. sist. sanit. Navar.[serie en Internet]. 2006 [citado 12 Ago 2002]; 29 (suppl. 3): [aprox. 3 p.]. Disponible en:http://www.cfnavarra.es/salud/anales/textos/vol29/ sup3/suple3a.html

Definicionesdemedicina.com [página en Internet].2011. [citado 15Abril de 2013]. Dis ponible en: http://www.definicionesdemedicina.com/rinoplastia-cerrada/

Declaración universal de los derechoshumanos [monografía en Internet].New York: ONU; 2012.[citado 15Abril de 2013]. Disponible en: http://www.un.org/es/documents/udhr/

Guzrnán Mora F. El acto médico: consideraciones esenciales. Rev. Col. de Resp. Medlegal. 1998; 4(2): 13-24

Rae.es[página en Intemet]. Madrid: RAE;2011. [citado 15Abril de 2013]. Disponible en: www.rae.es

ONU. Oficina del Alto Comisionado de las Naciones Unidas para los Derechos $\mathrm{Hu}$ manos. Declaración sobre los principios fundamentales de justicia para las víctimas de delitos y del abuso de poder; adoptada por la Asamblea General en su resolución 40/34, de 29 de noviembre de 1985 [monografía en Internet]. New York: ONU; 2007. [citado 15Abril de 2013]. Disponible en:http://www2.ohchr org/spanish/law/delitos.htm

senado.gov.ar|página en Intemet].Buenos Aires: 2012. [citado I5Abril de 2013]. Disponible en: http://www.senado.gov.ar/web/acts/administrativa/normativa.php

\section{Jurisprudencia}

Colombia. Corte Constitucional. Sentencia T-534 de 1992 (Marzo 2)en el proceso de acción de tutela promovido por Jorge Alexander Moreno contra la omisión del "Batallón de Apoyo y Servicio para el Combate" No. 5 "Mercedes Abrego" de la Quinta Brigada del Ejército Nacional, con sede en Bucaramanga.

Colombia. Corte Constitucional. Sentencia C-228 de 2002(Abril 3) Demanda de in constitucionalidad contra el artículo 137 de la Ley 600 de 2000, por la cual se expide el Código de Procedimiento Penal.

Colombia. Corte Constitucional.Sentencia T-484 de 1992 (Agosto 11) derecho a la salud, derecho a la vida, derechos fundamentales, sida e Instituto de Seguros Sociales.

Colombia. Corte Constitucional. Sentencia T-395 de 1998,declaración de insubsistencia en empleos de libre nombramiento y remoción-no motivación

Colombia. Corte Constitucional. Sentencia T-597 de 2001 (Junio 7)derecho a la salud del niño

Colombia. Corte Constitucional. Sentencia T-571 de 2002 (Julio 25) Seguro Socialnegligencia y morosidad para declarar la condición de jubilada, acción de tutelareconocimiento y pago de pensión de jubilación

Colombia. Corte Constitucional. Sentencia T-388 de 2002 (Mayo 20), Derecho a la salud. Solicitud practica trasplante de cornea prescrita por medico adscrito.

Colombia. Corte Constitucional. Sentencia C-370 de 2006 (Mayo 18)ley de justicia y paz-noconcede amnistía ni indulto/ley de justicia y paz-trámite legislativo como ley ordinaria

Colombia. Corte Constitucional. Sentencia C-029 de 2009, expediente D-7290 (28 de enero) demanda de inconstitucionalidad a varios decretos y leyes.

Corte Constitucional de Colombia. Sentencia C-409 de 2009 (Junio 17) Demanda de inconstitucionalidad contra el artículo 108 (parcial) de la Ley 906 de 2004. Citación del asegurador. Exclusivamente para efectos de la conciliación de que trata el artículo 103, la víctima, el condenado, su defensor o el tercero civilmente responsable podrán pedir la citación del asegurador de la responsabilidad civil amparada en virtud del contrato de seguro válidamente celebrado, quien tendrá la facultad de participar en dicha conciliación.

Colombia. Consejo de Estado. Sección tercera. Sala de lo Contencioso administrativo. Sentencia 7449 del 26 de febrero de 1993 Lesiones leves y daño moral

Colombia, Consejo de Estado. Sección Tercera, Sala de lo Contencioso Administrativo Sentencia 13477 del 02 de mayo de 2002. Responsabilidad por el ejercicio de actividades peligrosas

Colombia. Consejo de Estado. Sección Tercera, Sala de lo Contencioso Administrativo, Sentencia 16696 del 03 de mayo de 2007, C.P. Enrique Gil Botero. Principio de equidad, daño especial y justicia material.

Colombia. Consejo de Estado. Sala de lo Contencioso Administrativo, Sección Tercera, C.P. Ruth Stella Correa Palacio, Sentencia 18.433, del 3 de febrero de 2010 Responsabilidad médica obstétrica.

Colombia. Consejo de Estado. Sección Tercera, Sala de los Contencioso Administrati vo, sentencia 19963 del 28 de mayo de 2011. Rojas Betancourth. Responsabilidad por falla médica.

Colombia. Corte Suprema de Justicia. Sala de Casación Civil, sentencia 5507. del 30 de enero de 2001, M.P. Fernando José Ramírez Gómez. Responsabilidad civil extracontractual. 